\title{
MARÍA JESÚS RUBIERA Y SUS ESTUDIOS SOBRE LA ARQUITECTURA ISLÁMICA: LITERATURA DE PALACIOS Y JARDINES.
}

\author{
Gonzalo M. BORRÁS GUALIS \\ Universidad de Zaragoza
}

Cuando en el curso 1979-1980 introdujimos en los planes de estudio de la licenciatura en Filosofia y Letras (Sección de Historia) de la universidad de Zaragoza la asignatura optativa de Arte Musulmán e Hispanomusulmán éramos conscientes de la escasa atención que se concedía entonces a esta materia en la docencia universitaria española, excepción hecha de las universidades de Madrid y de Granada, y ello a pesar del importante legado artístico que el Islam ha dejado sobre el solar español.

En la universidad de Zaragoza existran razones de peso para promover esta docencia y que justificaban nuestra inquietud por estos temas, que abarcaban desde la vieja tradición de la escuela arabista zaragozana de los Francisco Codera, Julián Ribera y Miguel Asín Palacios hasta la por aquel momento trepidante actividad restauradora en el palacio islámico de La Aljafería a cargo del arquitecto Francisco íñiguez Almech. Pero a la vez teníamos conciencia de las dificultades para implantar una docencia sin la adecuada dotación de un profesor especializado en el tema y de la que hube de hacerme cargo sin ser arabista ni dedicarme a la arqueología islámica, con el escaso bagaje intelectual de mis investigaciones sobre arte mudéjar aragonés.

$\mathrm{Si}$ antepongo todo esto es para explicar cómo comencé a interesarme por los estudios de María Jesús Rubiera y para contextualizar de modo más preciso la incidencia que sus trabajos han tenido en la actividad docente de la asignatura de Arte Musulmán e Hispanomusul- 
mán de nuestra universidad de Zaragoza, que a partir del año 1982 cuenta ya con la nueva titulación de licenciatura en Historia del Arte. De lo dicho se habrá colegido que no se trata ahora de ofrecer una glosa desde el punto de vista del investigador sino del docente universitario.

Aunque mi primera referencia corresponda a otro aspecto de la valoración de la obra de Maŕa Jesús Rubiera, y sin ánimo de ingerirme en coto ajeno, no puedo omitir una alusión a la trascendencia de su trabajo en torno a «Los poemas epigráficos de Ibn al-Ŷyyāb en la Alhambra», publicado en el año 1970 en la extinta revista Al-Andalus, ya que fue mi primer encuentro con su investigación, hasta que todos pudimos disponer de la edición monográfica sobre Ibn al-Ŷyyyāb del año 1982, editada por el Patronato de la Alhambra. Como se puede inferir, atendido el objetivo de mi docencia universitaria, en esta entrega de María Jesús Rubiera yo no valoraba tanto la corrección de la tesis del maestro don Emilio Garcfa Gómez sobre Ibn Zamrak como el único poeta de la Alhambra, como el hecho de poder contar con la edición de unas fuentes árabes primordiales para los comentarios de texto.

En concreto los cuatro poemas de la torre de la Cautiva nos servían no sólo para definir el cambio de función entre las torres nazaríes del siglo XIII, de carácter estrictamente militar, y las del siglo XIV, de carácter mixto ("Calahorra que contiene un palacio"), sino en un ámbito mucho más general, de carácter estético, para profundizar en el papel que juega la superficie en la configuración del espacio musulmán así como para enfatizar la omnipresencia de la ornamentación islámica sobre cualquier tipo de soporte material. Con este proposito cuántas veces he recurrido en mis lecciones a este fragmento del poema del tercer ángulo en la torre de la Cautiva, según la traducción de Marfa Jesús Rubiera:

"Es un palacio en el cual el esplendor está repartido entre su techo, su suelo y sus cuatro paredes;

en el estuco y en los azulejos hay maravillas, pero las labradas maderas de su techo aún son más extraordinarias"

Si he antepuesto esta consideración es con el objeto de que se valore mejor el júbilo con que saludamos en mis clases la primera entrega de su obra, básica para la docencia universitaria, sobre $L a$ 
arquitectura en la literatura árabe. Datos para una estética del placer, en su edición del año 1981, realizada por la Editora Nacional. Junto con el Corán, en la versión española de Juan Vernet, de editorial Planeta, este pequeño gran libro de María Jesús Rubiera de la Editora Nacional constitúa una herramienta de trabajo insustituible para introducirnos en el pensamiento y en la cultura del Islam. Su lectura producía siempre entre los alumnos una profunda fascinación, que se acrecentaba sin duda al hallarse incluido el libro en la rara serie de la "Biblioteca de visionarios, heterodoxos y marginados".

Todos advertíamos dos valores fundamentales en esta obra: de un lado su carácter de antología de textos y documentos árabes sobre el arte y la arquitectura del Islam y de otro la excelente introducción que los propios comentarios de María Jesús Rubiera van ofreciendo para entender mejor las principales tipologías de la arquitectura del Islam.

De todos es sabido la importante función ancilar que en la docencia universitaria cumplen hoy día las colecciones de fuentes y documentos. En una aproximación al significado de cualquier obra de arte es preciso partir de la consideración de los factores extrínsecos, es decir, del pensamiento y de la cultura de la sociedad a la que corresponde y, asimismo, de aquellos agentes artísticos que hicieron posible la obra de arte. Para ello es inexcusable recurrir a las fuentes literarias de la época.

Nunca se ponderará suficientemente la laguna que en este sentido vino a llenar la antología de María Jesús Rubiera. Bastará con mencionar en este sentido que las fuentes árabes para la historia del arte islámico no habían sido contempladas ni en la prestigiosa colección norteamericana de los años setenta, editada por la Prentice Hall, titulada Sources and documents in the History of Art Series, bajo la direccion de H. W. Janson, ni tampoco en la excelente colección española de los años ochenta, editada por Gustavo Gili, titulada Fuentes y documentos para la Histona del Arte, bajo la dirección de Mireia Freixa, Joaquim Garriga y Joaquín Yarza.

Pero esta notable condición de obra única que concurre en la antología literaria de María Jesús Rubiera, y que constituiría por sí misma mérito más que sobrado para la estimación de un libro, se avalora en grado sumo con el acertado criterio de los textos antologizados $\mathrm{y}$, sobre todo, de los sugerentes comentarios personales de 
introducción a los mismos, que convierten a esta obra en un excelente vademecum para una primera aproximación al arte y a la arquitectura del Islam. Nosotros la utilizamos en clase para este propósito junto con la obra de Titus Burckhardt, El arte del lslam, en la versión española editada por Olañeta en 1988.

Precisamente una de las mayores dificultades que implica el estudio de la asignatura de Arte Musulmán e Hispanomusulmán para los alumnos, que se hallan inmersos por nacimiento y formación en la cultura occidental europea, es el paulatino proceso de mentalización para entrar en contacto con una estética oriental, proceso al que hay que dedicar inicialmente varias semanas de clase, puesto que es necesario dar la vuelta al revés, como si de un calcetín se tratase, a los presupuestos de la estética occidental europea, en la que nos hallamos instalados culturalmente.

Y esta dificultad se encuentra magnificamente salvada en la obra de María Jesús Rubiera desde su espléndida introducción, en la que la autora va desgranando los nuevos presupuestos de esta estética oriental, de una arquitectura concebida como "objeto de placer para los sentidos", de un arte cuyos propósitos son tan diferentes a los de la cultura occidental cristiana. Algunas de sus apreciaciones en esta introducción, que luego están desarrolladas con pormenor para cada tipología arquitectónica en los diferentes capítulos en que se organiza el libro, alcanzan cotas de sutil penetración al contrastarse con la estética occidental. Baste esta muestra: "Nunca la arquitectura occidental pensó en el ofdo, pobre victima que a lo que más puede aspirar es a la insonorización, pero jamas sera arrullado por sonidos nacidos de la arquitectura: en la estética arabe st, incluso las cúpulas han de tener ecos gratos como arrullos búsquese este dato en las descripciones de los palacios andalusies)".

El libro dedica los primeros epígrafes a aquellos arquetipos ideales desarrollados en la literatura árabe sobre palacios míticos, sobre Salomón como gran constructor o sobre ciudades fantásticas, para luego desgranar las fuentes primordiales sobre los monumentos más importantes del Islam - con tratamiento individual para palacios, jardines, baños $y$ mezquitas- tanto en Oriente como en al-Andalus, $y$ un epigrafe monográfico sobre Granada. Este planteamiento tiene la virtud de permitir apreciar mucho mejor la pervivencia de los arquetipos ideales 
en las fuentes árabes a lo largo del tiempo, tema al que María Jesús Rubiera siempre ha concedido particular atención (Véase, por ejemplo, su aportación sobre "Arquetipos ideales de la ciudad árabe", en La ciudad islámica, Zaragoza, Institución "Fernando el Católico", 1991, pp. 57-64). Por todo ello contribuye de manera muy eficaz al siempre diff́cil deslinde entre fantasía y realidad en los textos literarios árabes.

Creo que lo dicho deja testimonio claro de la utilidad de este libro y de su frecuente uso por los alumnos de la universidad de Zaragoza. Por esta razón cuando se produjo el lamentable desmantelamiento de la Editora Nacional, temimos todos por su propia supervivencia y no fue menor el júbilo ante su segunda edición, a cargo de la editorial Hiperión, en el año 1988, esta vez además ampliada con un atinado capítulo para la época de las primeras taifas, en el que se recogen nuevos textos sobre los palacios de Al-Ma'mūn en Toledo y de Al-Mu'tamid en Sevilla. Tampoco sorprenderá, pues, tras cuanto se lleva ya apuntado, que la siempre atenta industria editorial italiana haya acometido una traducción de este libro, en edición genovesa de Marietti, en 1990.

Quiero todavía añadir una observación, que no considero irrelevante para la valoración de esta obra. Si tenemos en cuenta el divorcio que en los estudios sobre arte islámico en España se constata en los últimos tiempos entre arabistas, arqueólogos, arquitectos e historiadores del arte, que hace tan difícil, en particular para los docentes, cohonestar las aportaciones científicas procedentes de tan diversos campos de investigación, este tipo de contribuciones de carácter escolar adquieren todavía mayor relevancia, en especial por lo que suponen de generosi. dad intelectual hacia una comunidad cientifica muy heterogénea, que no siempre tiene facilidades para acceder a este tipo de fuentes. Nunca se elogiará bastante la grandeza de espíritu que encierra el sacrificio de la legítima brillantez del trabajo especializado, poniendo el conocimiento al alcance de un público mucho más amplio.

Pero no nos encontramos solamente ante un corpus básico de fuentes árabes para la arquitectura islámica, sino ante una arabista que desde el punto de vista del conocimiento y estudio de estas fuentes literarias ha profundizado en la comprensión del arte y de la arquitectura del Islam. Y, en esta línea, el peso de la literatura en la comprensión del arte islámico tiene mucha más trascendencia de la que se pudiera 
pensar a priori, en todo caso más que en otras culturas, ya que el propio pensamiento islámico ha subrayado la concordancia estructural entre el lenguaje literario y el lenguaje artístico. En el poema de Ibn al-Ŷayyāb, del que hemos citado un fragmento anteriormente, se dice en este sentido:

"parecen poéticas imágenes, paranomasias y trasposiciones los enramados $e$ incrustaciones".

Si el pensamiento cristiano ideó, siguiendo la tradición neoplatónica, el método analógico para poder elevarse de la contemplación de la realidad material al mundo espiritual, en el pensamiento del Islam la estructura de la metáfora literaria ha podido convertir al jardín en un paraíso en la tierra. Como constatación, una de las últimas aportaciones de la profesora Marfa Jesús Rubiera lleva un título bien revelador: "ll giardino islámico como metafora del paradiso" ( en Il giardino islamico. Architettura, natura, paesaggio, edición de Attilio Petruccioli, Milano, Electa, 1994, pp. 13-24). Es decir, el peso de la literatura árabe en la cultura islámica, $\mathrm{y}$ por tanto en el arte, nos permite establecer un importante matiz diferenciador entre el carácter "simbólico" del arte occidental y el "metafórico" del arte islámico.

Por todo ello creo que las contribuciones de la profesora María Jesús Rubiera en esta parcela de las fuentes literarias árabes para el arte del Islam, que a alguien se le pudiera antojar menor, en este contexto que se ha planteado se alejan del carácter ancilar de las antologías para elevarse a la categoría de método de trabajo para la lectura e interpretación del arte islámico, al que tanto está aportando con sus puntos de vista desde las fuentes literarias. 